\title{
Poderosos chefões: a influência do perfil do líder sobre a disciplina da bancada
}

\author{
Powerful bosses: an influence of the leader's profile on a \\ bench discipline
}

\author{
Leonardo Rodrigues de Morais \\ José Alexandre da Silva Júnior \\ Ranulfo Paranhos dos Santos Filho
}

\section{Resumo}

Qual o efeito do perfil dos líderes sobre a disciplina partidária da bancada? O objetivo desse trabalho é estimar a influência do perfil dos líderes no comportamento das suas bancadas. Os principais esforços metodológicos consistem em montar o perfil do líder e mensurar o comportamento da bancada. Para realizar a análise utilizaremos estatística descritiva e multivariada. $\mathrm{O}$ perfil dos líderes será composto por duas dimensóes, expertise e credibilidade. A unidade de análise serão os parlamentares das $\left(51^{\circ} \mathrm{e}\right.$ $52^{\circ}$ ) Legislaturas da Câmara dos Deputados. Os resultados da pesquisa mostram que a média de disciplina dos parlamentares com líderes que possuem mais credibilidade é mais alta. Porém, o mesmo não pode se dizer da média de disciplina dos líderes com maior grau de prestígio. Em resumo, líderes com mais credibilidade comandam bancadas mais disciplinadas.

\section{Palavras-chave}

Disciplina Partidária; Seleção de Agentes; Líderes de Bancada.

\begin{abstract}
What is the effect of the leaders' profile on the party discipline of the bench? The objective of this work is to estimate the influence of the profile of leaders on the behavior of their teams. Therefore, the main methodological efforts are to set the profile of the leader and measure the behavior of the bench. To perform the analysis we will use descriptive and multivariate statistics. The unit of analysis will be the parliamentarians of the Legislatures (51st and 52nd) of the Chamber of Deputies. The results of the analysis show that the average discipline of parliamentarians with more credible leaders is higher. However, the same can not be said of the average discipline of leaders with a greater degree of expertise. In short, leaders with more credibility run more disciplined boards.
\end{abstract}

\section{Keywords}

Partisan Discipline; Selection of Agents; Bench Leaders. 


\section{Introdução}

A literatura norte-americana, em especial, alguns brasilianistas (AMES, 2003; MAINWARING, 2001), tem apontado que as regras eleitorais no Brasil favorecem a candidatura altamente centrada no candidato e que os políticos brasileiros estariam mais preocupados com seus interesses pessoais do que propriamente em cumprir uma agenda legislativa. Para Mainwaring (2001) e Ames (2003), as consequências das regras eleitorais levam a um sistema atomizado, onde indivíduos fazem apenas o que é melhor para si, mesmo contra os interesses dos seus pares ou do seu líder.

No entanto, alguns autores têm caminhado em direção oposta a esse diagnóstico sobre o comportamento do parlamentar brasileiro. Para Figueiredo e Limongi (2001), os partidos não são meros agrupamentos de indivíduos preocupados com suas próprias demandas. Não há lugar para parlamentares fisiologista. Segundo Lyne (2008), as lideranças partidárias conseguem exercer forte influência sobre os parlamentares. Portanto, parte da literatura desafia o diagnóstico de que os parlamentares brasileiros não obedecem a liderança e que o Congresso carece de disciplina.

De acordo com Carey (2007), uma combinação carrots and sticks ou recompensas e punições administrados pelos líderes é necessária para garantir a disciplina das bancadas. Parlamentares sozinhos enfrentam sérios problemas de coordenação. Pereira e Muller (2003) argumentam que é preferível seguir as ordens da liderança caso o parlamentar pretenda se reeleger (PEREIRA e MULLER, 2003). Hoje os líderes partidários têm poder de agenda, podem confrontar as comissóes e centralizam a alocação de recursos parlamentares. Em outros termos, a liberação de recursos para as bases dos parlamentares é controlada em parceria com o poder Executivo. O objetivo é garantir a aprovação da agenda legislativa do Executivo (FIGUEIREDO e LIMONGI, 2001; HIROI e RENNÓ, 2014; LYNE, 2008).

Diante desse cenário cabe perguntar: qual o efeito do perfil dos líderes sobre a disciplina partidária da bancada? $\mathrm{O}$ objetivo desse trabalho será estimar a influência do perfil dos líderes no comportamento das suas bancadas. Metodologicamente, utilizamos estatísticas descritiva e multivariada para definir o perfil do líder e mensurar o comportamento da bancada, a partir de um banco de dados sistematizado com informaçôes obtidas no site da Câmara dos Deputados ${ }^{1}$.

\footnotetext{
${ }^{1}$ Site da Câmara dos Deputados. Disponpivel em: <http://www2.camara.leg.br>. Acesso em: 07 abr. 2018 .
} 


\section{Disciplina partidária e governabilidade}

Especialmente após a redemocratização de 1988, o sistema partidário e as regras eleitorais no Brasil tornaram-se alvo de cientistas políticos brasileiros e norteamericanos (AMES, 2003; AMORIM e SANTOS, 2001; CAREY, 2007; FIGUEIREDO e LIMONGI, 2001; FREITAS, 2013; HIROI e RENNÓ, 2014; LYNE, 2008; MAINWARING, 2001; NICOLAU, 2000). Para Lucas e Samuels (2010), o debate sobre a política partidária do Brasil apresenta duas fases. A primeira, afirma que os partidos no Brasil são fracos e o sistema partidário "incipiente" (MAINWARING, 2001). Segundo Lucas e Samuels (2010), essa visão, em larga medida, ganhou força devido a uma interpretação que relaciona a cultura, a história e a política brasileira. Empiricamente, ela é apoiada pela alta taxa de volatilidade eleitoral, mudança desenfreada de partido e um sistema partidário ainda instável.

$\mathrm{O}$ argumento é que o sistema eleitoral brasileiro cria incentivos desfavoráveis tanto à disciplina quanto à governabilidade (AMES, 2003; MAINWARING, 2001). No entanto, outros trabalhos têm indicado a figura do líder como determinante para a governabilidade e para fazer cumprir a agenda legislativa do Executivo (FIGUEIREDO e LIMONGI, 2001; FREITAS, 2013). O líder aparece como peça fundamental na disciplina partidária dos parlamentares (AMORIM e SANTOS, 2001; CAREY, 2007; FIGUEIREDO e LIMONGI, 2001; FREITAS, 2013; LYNE, 2008).

Pioneiros, Figueiredo e Limongi (2001) chamam atenção para a forte unidade dos partidos nas votaçóes nominais na Câmara dos Deputados brasileira. Com isso, contestam o diagnóstico estabelecido sobre o desempenho dos sistemas presidencialistas em geral e o funcionamento do presidencialismo brasileiro em particular. Segundo eles, o Congresso brasileiro náo pode ser visto como um obstáculo à aprovaçáo da agenda legislativa do Executivo (FIGUEIREDO e LIMONGI, 2001). Ao contrário do que se divulga, os governos recentes têm obtido considerável grau de sucesso no legislativo.

Para Figueiredo e Limongi (2001) o sucesso da agenda legislativa do Executivo só é possível graças à disciplina partidária na Câmara dos Deputados. Eles são taxativos ao dizer que a força institucional dos presidentes pós-1988 aumentou consideravelmente, o que fez elevar a taxa de sucesso de todos eles, com exceçấo do ex-presidente Fernando Collor. Mesmo com um alto número de projetos de lei com origem no poder legislativo, a taxa de sucesso do executivo é significativamente maior. Caso se leve em conta os projetos que foram apresentados e sancionados no mesmo ano, o Executivo predomina sobre o Legislativo, isto é, propóe e sanciona 
mais projetos de lei que o Legislativo, "[...] apenas $17 \%$ das leis de iniciativa do Legislativo foram sancionadas no mesmo ano em que foram apresentadas, ao passo que $86 \%$ das leis do Executivo foram apresentadas e sancionadas no mesmo ano" (FIGUEIREDO e LIMONGI, 2001, p. 105). De acordo com Freitas (2014), o Executivo também mostra sua força ao manter suas preferências a partir da manutenção dos seus vetos. Esse é um lugar privilegiado para observar os acordos feitos entre Executivo e os líderes que integram a coalizão.

Porém, de acordo com Ames (2003) esse predomínio do Executivo não corresponde exatamente ao triunfo dos líderes de bancadas. Para Ames, "a influência se dá de baixo para cima, dos membros do partido para as lideranças e náo de cima para baixo" (AMES, 2003, p. 262). O pressuposto é que o líder negocia sua indicaçáo com os parlamentares ex-ante. $\mathrm{Na}$ ausência do consenso, ele abdica da indicação de voto, liberando a bancada para votar à sua maneira. Ames (2003) também considera que os presidentes brasileiros não são atores dominantes, seu pressuposto é de que desde o governo Sarney até o primeiro mandato do Fernando Henrique Cardoso (FHC) a maioria das proposiçóes do Executivo saem do Congresso com muitas modificaçôes ou não chegam sequer a serem apreciadas.

O sucesso dos presidentes é geralmente medido pelas taxas de aprovação dos projetos do Executivo submetidos a votaçóes nominais (AMES, 2003). No entanto, essa análise esconde os dados da não decisão. Quando há uma oposição forte ao projeto, ele pode nem chegar a ser aprovado. Ou seja, “o ‘baláo-de-ensaio’ lançado pelo presidente pode provocar tão violenta rejeição no Congresso que ele acaba desistindo de enviar um projeto formal" (AMES, 2003, p. 239). Portanto, a disciplina legislativa pode ser consequência dos incentivos proporcionados pelos programas de benefícios e obras públicas patrocinadas pelo governo. Vale dizer que as principais moedas dos líderes são: 1) indicação para as comissóes e 2) poder de agenda (pedido de urgência). Parte-se do pressuposto de que eles podem utilizá-las em favor do Executivo.

Para compreender esse imbróglio, Nicolau (2000) analisou a variação da disciplina considerando a taxa de apoio do Executivo no Congresso, as proposiçóes de interesse do Executivo e o efeito da indisciplina e das ausências nos resultados das votaçóes. Como as proposiçóes legislativas exigem quórum diferenciado para serem aprovadas, Nicolau (2000) dividiu as votaçóes por tipo de proposição: 1) emendas constitucionais; 2) leis complementares; e 3) legislação ordinária. As análises levaram Nicolau (2000) a separar os partidos em três grupos conforme as taxas médias de disciplina dos partidos. No primeiro grupo encontra-se os partidos com médias 
próximas a $100 \%$ de disciplina, seriam o PT e o PCdoB. O segundo grupo é composto pelos partidos cujas as taxas variam em torno de 90\%: PFL, PDT, PSDB, PSB e PTB. No terceiro grupo encontram-se os que possuem taxas mais baixas, em torno de 80,0\%: PPR/PPB, PMDB e PL. Esses indícios apontam que existe uma boa margem para exceçôes, seja qual for a regra geral.

Por fim, Amorim e Santos (2001) analisaram o uso de recursos orçamentários e de poder de agenda do Executivo para reunir apoio legislativo. A principal hipótese dos autores é que quanto mais personalizado é o voto, mais individualista é a conduta dos políticos. Inversamente, quanto menos personalizado, mais partidário é o comportamento dos legisladores. Para os autores, a disciplina partidária no Brasil deve ser explicada, principalmente, pelas estratégias de formação de coalizão parlamentar e de distribuição de recursos de patronagem. Mesmo sendo eleito em âmbito nacional, o presidente precisa harmonizar os interesses parlamentares regionais representados. Com preocupação semelhante, Hiroi e Rennó (2014 e 2017) buscam examinar o efeito da gestão das coalizóes no sucesso da agenda legislativa do executivo. O foco é identificar as estratégias de obstrução da agenda e as manobras operadas pelo Executivo para miná-las. Hiroi e Rennó (2017) evidenciam que a lógica de construção de coalizóes não se reduz ao quanto maior, melhor. $\mathrm{O}$ tamanho exagerado associado à heterogeneidade de interesses pode minar as pretensóes do executivo.

Embora o foco desses últimos trabalhos seja a acomodação de interesses via construção de coalizões, nenhum deles nega a importância dos líderes na coordenação das bancadas. Ao que parece, as análises mais recentes adotam a perspectiva da ação coletiva das bancadas. Porém eles apontam que o regimento nem sempre joga a favor da presidência (HIROI e RENNÓ, 2014 e 2017; FREITAS, 2013). Há um processo de negociação que nem sempre é bem sucedido. Parte da variação do apoio à agenda legislativa do executivo e da disciplina partidária pode ser explicada por esse fato.

\section{Dos lideres}

No Brasil, de acordo com Figueiredo e Limongi (2001, p. 47) “os líderes se encontram em posição privilegiada para influir na direção dos trabalhos legislativos". Além disso, os autores defendem que o colégio de líderes é fundamental para garantir o acesso dos parlamentares aos benefícios oriundos de outros centros de poder, leiase, o Executivo. Pereira e Mueller argumentam que "os líderes partidários formam a ponte que liga os parlamentares individuais ao Executivo" (PEREIRA e MUELLER, 2003, p. 739). Para Pereira e Rennó, "os deputados agem em conformidade com as 
posiçôes das suas lideranças partidárias como uma forma de ter acesso aos benefícios políticos e financeiros controlados pelos líderes e centralizados no Executivo" (PEREIRA e RENNÓ, 2001, p. 12).

Para Lyne (2008), a liderança partidária consegue exercer forte influência sobre o parlamentar em fazer cumprir as regras, elevando a unidade partidária. Lyne (2008), examina o comportamento legislativo numa série temporal dividida em dois períodos: pós-guerra e os dias atuais. A autora demonstra que contemporaneamente no Brasil os líderes partidários têm feito cumprir a unidade partidária e tem punido o comportamento personalista, além de beneficiar aqueles que seguem as orientaçóes da liderança. Segundo Lyne (2008), um importante corpo de pesquisadores tem argumentado que no Brasil a candidatura é extremamente centrada no candidato e que as regras eleitorais criam fortes incentivos ao individualismo e que isso pode afetar a capacidade do partido de oferecer aos eleitores uma alternativa para o programa nacional. Enquanto o parlamentar esforça-se para conseguir sua reeleiçáo, o partido esforça-se para melhorar as perspectivas do coletivo.

Portanto, fica a pergunta: a quem o legislador obedece, ele segue o programa partidário, coletivo, colhendo frutos nacionais ou desafia o partido em busca de seus próprios interesses?

Teoricamente, Lyne (2008) argumenta que a diferença entre os padróes de votação de dois períodos históricos deve-se à criação de regras que fortaleceram as lideranças. No entanto, há claramente várias outras possibilidades não exploradas pela autora. Por exemplo, o conjunto de atributos dos parlamentares que formam as bancadas.

Estudos apontam que as regras eleitorais no Brasil favorecem o comportamento individual do legislador frente ao partido e que o personalismo político enfraquece a unidade partidária. Essa visão tem sido altamente desafiada, exibindo que os líderes exercem poderes significativos e que os partidos são considerados internamente unificados, diferente do que a literatura apontava (FIGUEIREDO e LIMONGI, 2001; LYNE, 2008).

Segundo Lyne (2008), no período pós-guerra (1945-64), os partidos brasileiros não se mostravam suficientemente coesos e a capacidade do líder em fazer cumprir as regras e elevar os níveis de unidade partidária eram baixos. Contudo, atualmente, os líderes conseguem elevar os níveis de unidade partidária, possuem prerrogativas significativamente fortes. Dessa forma, conseguem disciplinar aqueles que quiserem obter recursos para suas bases ou que almejam uma carreira partidária. 
Hoje a alocação de recursos é altamente institucionalizada e centralizada nas mãos dos líderes e a decisão para a liberação dos recursos ao parlamentar é controlada pelo líder do partido em parceria com o poder Executivo (FIGUEIREDO e LIMONGI, 2001; LYNE, 2008). Atualmente as lideranças partidárias possuem muito mais poderes que no período anterior ao pós-guerra. Contemporaneamente, os líderes coordenam a agenda política no Congresso e o executivo dispóe de maior apoio que no período anterior. Em resumo, Lyne (2008), afirma que os partidos no Brasil importam e que eles são coesos - bem como a liderança consegue exercer uma forte influência sobre os legisladores frente aquilo que o partido determina em votação no Congresso.

Qual o custo da disciplina de cada parlamentar diante do suposto dilema em satisfazer as "[...] reivindicaçôes das suas respectivas circunscriçôes eleitorais [...] e simultaneamente ter que seguir a indicação dos seus líderes partidários"? (PEREIRA e MULLER, 2003, p. 764). Para Lyne (2008), parlamentares que conseguem sobreviver politicamente sem ter acesso aos benefícios políticos controlados pelos líderes, tendem a desobedecer às ordens da liderança em detrimento de suas próprias posições ideológicas. Sendo o contrário verdadeiro, "[...] o sistema político brasileiro condensa essas duas diferentes e antagônicas forças e incentivos institucionais" (PEREIRA e MULLER, 2003, p. 737).

Deste modo, o trabalho procura responder a seguinte questão de pesquisa: qual a influência do perfil do líder sobre a disciplina da bancada? Líderes mais credible e prestigiosos conseguem comandar bancadas mais disciplinadas? Do ponto de vista acadêmico, a pesquisa procura diminuir uma lacuna analítica de trabalhos que analisem de forma sistemática os dilemas de ação coletiva nas bancadas, elaborando o perfil das lideranças mais aptas em resolver tais dilemas.

Nossa preocupaçáo revela em alguma medida um posicionamento teórico. Para nós, líderes de bancada importam. Em outras palavras, acreditamos que eles sejam capazes de induzir, em alguma medida, um comportamento disciplinado. Todavia, o trabalho não esclarecerá qual o mecanismo dessa indução. Deixamos em aberto a possibilidade de ser resultado do emprego de recompensas e puniçóes ou de negociações menos acirradas com as bancadas. O objetivo aqui é apenas mostrar que o selecionado faz diferença. Os líderes não são iguais e isso reflete-se diretamente no comportamento dos seus comandados.

Segundo Olson (1999), a principal finalidade de uma associação ou grupo é alcançar objetivos inacessíveis a qualquer um de seus membros. Todavia, a simples 
criação do grupo não é garantia de que a meta será atingida. A parte mais difícil é fazer com que todos ajam para garantir o benefício. Por um lado, os indivíduos precisam estar cientes de que sua ação não é desprezível para provisão do benefício. Eles precisam estar convencidos de que a estratégia de desfrutar do benefício, sem fazer qualquer ação, não está disponível. Em termos mais técnicos, os indivíduos precisam "desapontar" a racionalidade instrumental e descartar o comportamento oportunista ou free rider (ELSTER, 1994; HINDESS, 1984).

Como não é possível uma auto-coordenação para promoção de benefícios coletivos, uma saída possível é instituir uma autoridade com função de organizar e promover esses benefícios (OSTROM, 1999). A ideia é selecionar um agente com a função de coordenar e monitorar a ação do grupo. Dessa forma, garantir que a ação coletiva de fato aconteça. Porém, a utilização dessa estratégia não está livre de quaisquer riscos, os dois principais: 1) seleção adversa e 2) risco moral (BENDOR et al., 2001). Precisamente, a estratégia pode falhar por atrair e selecionar agentes não críveis e/ou preparados para assumir a função, além disso, pode errar por permitir que o selecionado aja em desacordo com as expectativas do grupo (COX e McCUBBINS, 1993; MELO, 2001).

Empiricamente, as bancadas na Câmara são coletividades que enfrentam vários problemas de ação coletiva. Enquanto grupo, o objetivo delas é garantir os benefícios gerados pela disciplina partidária (CAREY, 2007; FIGUEIREDO e LIMONGI, 2001; LYNE, 2008;). Para tanto, precisa coibir os impulsos individualistas criados pelo sistema eleitoral e pelo presidencialismo de coalizão (AMES, 2003; MAINWARING, 2001;). Como visto, a literatura se divide quanto ao assunto, apenas parte acredita que as bancadas conseguem vencer esse desafio (LYNE, 2008; PEREIRA e MULLER, 2003). De qualquer modo, a parte crédula aposta também que os líderes são a chave do sucesso. Não sem razão, o regimento da Câmara centraliza os trabalhos e confere aos líderes poder de agenda (FIGUEIREDO e LIMONGI, 2001).

Claramente, assume-se aqui a perspectiva de que os líderes importam. Porém, considera-se que a bancada nem sempre seleciona os melhores. Em outros termos, aposta-se na ideia de que parte da indisciplina da bancada é explicada por problemas de seleção adversa (SILVA JR. et al., 2013). Nesse sentido, as bancadas que conseguem maximizar sua escolha têm níveis de disciplina mais altos. O desafio maior é selecionar os agentes mais bem preparados e mais críveis, do contrário, o nível de indisciplina diminui e a bancada pode desperdiçar recursos importantes para sobrevivência política dos parlamentares. Os líderes precisam inspirar confiança nos 
seus comandados e precisam ter credibilidade. Ao mesmo tempo, é plausível que eles também necessitem conhecer bem o funcionamento da Casa. Mais que qualquer outro, os líderes precisam demonstrar compromisso com metas coletivas e eficiência na negociação com outros atores da arena decisória.

\section{Metodologia e desenho de pesquisa}

Esta seção apresenta os procedimentos metodológicos, resumo das variáveis, desenho de pesquisa e descreve as técnicas estatísticas utilizadas. A seção está dividida em duas partes: a primeira, descreve as variáveis e a metodologia, em seguida, os procedimentos estatísticos adotados para análise dos dados. Todas as informaçóes utilizadas nesta pesquisa foram retiradas do site da Câmara dos Deputados Federal ${ }^{2}$ e do Tribunal Superior Eleitoral $(\mathrm{TSE})^{3}$, e podem ser acessadas livremente por qualquer cidadão, de modo que possa garantir a transparência e replicabilidade do trabalho.

\section{Descrição das variáveis e metodologia}

A fim de facilitar a visualização das variáveis, hipóteses e objetivo do trabalho, o quadro abaixo sumariza o desenho de pesquisa:

\footnotetext{
2 Site da Câmara dos Deputados Federal. Disponível em: <http://www2.camara.leg.br/>. Acesso em: 07 abr. 2018.

${ }^{3}$ Site do Tribunal Superior Eleitoral. Disponível em: <http://www.tse.jus.br/>. Acesso em: 07 abr. 2018.
} 
Quadro 1 - Desenho de pesquisa

\begin{tabular}{|c|l|}
\hline Questáo de Pesquisa & Qual a influência do perfil dos líderes sobre a disciplina partidária da bancada? \\
\hline Objetivo Geral & O objetivo será estimar a influência do perfil dos líderes na disciplina partidária. \\
\hline \multirow{3}{*}{ Hipóteses } & $\begin{array}{l}\text { A credibilidade do líder exerce um efeito positivo e significativo sobre o nível de } \\
\text { disciplina partidária. }\end{array}$ \\
\cline { 2 - 2 } & $\begin{array}{l}\text { O prestígio do líder exerce um efeito positivo e significativo sobre o nível de } \\
\text { disciplina partidária. }\end{array}$ \\
\hline \multirow{2}{*}{ Variáveis } & Disciplina Partidária (VD) \\
\cline { 2 - 2 } Técnicas & $\begin{array}{l}\text { Credibilidade e Prestígio (VI’s) } \\
\text { Regressão Logística (Estima efeitos de variáveis independentes sobre a } \\
\text { dependente binária). }\end{array}$ \\
\hline
\end{tabular}

Fonte: Elaboração própria.

A disciplina partidária (VD) significa que o parlamentar vota conforme o indicado pela sua liderança. Por outro lado, o perfil dos líderes (VI) será constituído por dois fatores: 1) credibilidade e 2) prestígio. A credibilidade corresponde a redução de variáveis que sinalizam o compromisso do líder com a máquina partidária (tempo no partido + cargos no partido + migração partidária). A variável tempo no partido corresponde ao tempo de filiaçáo em anos ao partido; cargos no partido, representa os cargos exercidos pelo parlamentar na executiva do partido; e a variável migração partidária, se o candidato permaneceu no partido.

O prestígio é composto pela redução de variáveis que sinalizam o peso político do parlamentar que se torna líder (tempo de Câmara + experiência política + tipo do candidato). A variável tempo de Câmara, refere-se ao número de mandatos do parlamentar; experiência política, aos cargos eletivos conquistados; e tipo do candidato, se o parlamentar é incumbent ou challenger, respectivamente, se o parlamentar possui experiência na Câmara dos Deputados ou é um novato. A unidade de análise serão os parlamentares das $\left(51^{\mathrm{a}}\right.$ e $\left.52^{\mathrm{a}}\right)$ Legislaturas. Essas Legislaturas foram escolhidas por razóes operacionais e teóricas. As operacionais resumem ao fato da coleta de dados ter sido feira para realização de um trabalho maior, qual seja, uma dissertação sobre o tema. Vale dizer, por impossibilidade técnica, foi preciso realizar parte do procedimento manualmente, um esforço custoso para ser replicado para outros fins ${ }^{4}$. Quanto às teóricas, a razão principal é capturar

\footnotetext{
${ }^{4}$ Os dados utilizados para elaboração desse artigo foram trabalhados por Silva (2009) na construção da dissertação intitulada - As sementes da discórdia: regras e exceções da indisciplina partidária. Disponível em: <https://repositorio.ufpe.br/handle/123456789/1394>. Acesso em: 07 abr. 2018.
} 
um momento raro da nossa democracia recente. O período correspondente a essas legislaturas demarca uma transição de governo. Portanto, a escolha estabelece um controle natural na medida em que examina um período de troca de papéis entre governo e a oposição. Precisamente, na 51 a Legislatura o Executivo era comandado pelo PSDB na figura do presidente Fernando Henrique, na 52a o PT passa a ocupar esse posto, na figura do presidente Luiz Inácio. Dito isso, o quadro abaixo sumariza o conjunto de técnicas estatísticas utilizados na pesquisa e o resumo da descriçáo das variáveis. 
Leonardo de Morais, José Alexandre Júnior e Ranulfo Paranhos Filho

Quadro 2 - Resumo metodológico e das variáveis

\begin{tabular}{|c|c|c|c|c|}
\hline $\begin{array}{c}\text { Component } \\
\mathrm{e}\end{array}$ & \multicolumn{2}{|c|}{ Nomenclatura } & Descrição & $\begin{array}{c}\text { Mensuraçáa } \\
\text { o }\end{array}$ \\
\hline VD & \multicolumn{2}{|c|}{ Disciplina Partidária } & $\begin{array}{l}\text { Número de vezes em que seguiu do } \\
\text { líder }\end{array}$ & Discreta \\
\hline \multirow{6}{*}{ VI } & \multirow{3}{*}{ Credibilidade } & $\begin{array}{l}\text { Tempo no } \\
\text { partido }\end{array}$ & $\begin{array}{c}\text { Tempo de filiaçáo ao partido em } \\
\text { anos (líder) }\end{array}$ & Discreta \\
\hline & & $\begin{array}{l}\text { Cargo no } \\
\text { partido }\end{array}$ & $\begin{array}{c}\text { Cargos na executiva do partido } \\
\text { (líder) }\end{array}$ & Categórica \\
\hline & & $\begin{array}{l}\text { Migração } \\
\text { partidária }\end{array}$ & $\begin{array}{c}\text { Se o candidato permaneceu no } \\
\text { partido (líder) }\end{array}$ & Categórica \\
\hline & \multirow{3}{*}{ Prestígio } & $\begin{array}{l}\text { Tempo na } \\
\text { Câmara }\end{array}$ & Número de mandatos (líder) & Discreta \\
\hline & & $\begin{array}{l}\text { Experiência } \\
\text { política }\end{array}$ & Cargos eletivos conquistados (líder) & Categórica \\
\hline & & $\begin{array}{l}\text { Tipo de } \\
\text { candidato }\end{array}$ & Se incumbent ou challenger & Categórica \\
\hline \multirow{4}{*}{ VC } & \multicolumn{2}{|c|}{ Quórum } & $\begin{array}{c}\text { Tipo de quórum exigido para } \\
\text { aprovação da matéria }\end{array}$ & Categórica \\
\hline & \multicolumn{2}{|c|}{ Cargo no partido } & $\begin{array}{c}\text { Tempo de filiaçáo ao Partido em } \\
\text { anos (parlamentar) }\end{array}$ & \\
\hline & \multicolumn{2}{|c|}{ Tempo no partido } & $\begin{array}{l}\text { Exercício de cargo no partido } \\
\text { (parlamentar) }\end{array}$ & \\
\hline & \multicolumn{2}{|c|}{ Migração partidária } & $\begin{array}{c}\text { Se o candidato permaneceu no } \\
\text { partido (parlamentar) }\end{array}$ & \\
\hline \multirow{4}{*}{ Técnicas } & $\begin{array}{l}\text { Estatística } \\
\text { descritiva }\end{array}$ & Análise fatorial & Reduz dados & - \\
\hline & & $\begin{array}{c}\text { Análise de } \\
\text { conglomerados }\end{array}$ & $\begin{array}{l}\text { Agrupar casos a partir de carac- } \\
\text { terísticas que os tornam similares }\end{array}$ & \\
\hline & \multirow{2}{*}{$\begin{array}{l}\text { Estatística } \\
\text { inferencial }\end{array}$} & Teste $t$ & Compara as médias de dois grupos & - \\
\hline & & $\begin{array}{l}\text { Regressão } \\
\text { logística }\end{array}$ & $\begin{array}{c}\text { Estima efeitos de variáveis } \\
\text { independentes sobre a dependente }\end{array}$ & - \\
\hline
\end{tabular}

Fonte: Elaboração própria.

\section{Técnicas estatísticas}

O principal objetivo da pesquisa será estimar a influência do perfil dos líderes na disciplina partidária das bancadas. Portanto, os principais esforços metodológicos consistem em montar o perfil do líder e estimar a sua influência na disciplina partidária das bancadas. Para a construção do perfil do líder foi utilizada a técnica 
estatística de análise fatorial $(\mathrm{AF})^{5}$. Precisamente, a $\mathrm{AF}$ será utilizada para cumprir duas tarefas importantes: 1) observar o nível de variância compartilhada entre as variáveis que compóe cada fator e 2) construir os fatores que representam o perfil dos líderes de bancada. A partir dele, será possível classificar os líderes em categorias. Por exemplo, separar os mais críveis dos não críveis ou mais prestigiosos dos não prestigiosos.

Em seguida, é feita a análise de diferença entre duas condiçôes. O teste $t$ será útil para comparar as médias de disciplinas de bancadas lideradas por parlamentares mais críveis com os demais ${ }^{6}$. O mesmo espera-se fazer em relação ao fator prestígio. $\mathrm{O}$ que se deseja saber aqui é se a diferença entre as médias dos grupos de líderes críveis e/ou prestigiosos é grande o suficiente para aceitarmos a diferença entre eles.

Antes de estimar a regressáo logística, agrupamos os parlamentares e os líderes via análise de cluster. Os primeiros a partir do número de vezes que votaram com seus respectivos líderes. Portanto, separamos os parlamentares disciplinados dos desviantes. Já as lideranças foram agrupadas a partir dos fatores credibilidade e prestígio. Formamos quatro grupos de líderes: 1) confiáveis; 2) não confiáveis; 3) prestigiosos e 4) não prestigiosos. Por fim, usamos um modelo de análise de regressão logística para estimar o efeito do perfil dos líderes sobre o nível de disciplina da bancada $^{7}$. Por exemplo, calculamos a probabilidade de um parlamentar ser comando por um líder confiável e ser classificado como indisciplinado.

\section{Resultados e análises}

Inicialmente, para compor o perfil do líder, utilizamos análise fatorial e, em seguida, comparamos as médias dos líderes críveis e prestigiosos com os demais (não críveis e não prestigioso). Por fim, a análise de regressão estimará o efeito do perfil dos líderes sobre o nível de disciplina da bancada.

\footnotetext{
${ }^{5} \mathrm{O}$ principal objetivo da análise fatorial é reduzir uma grande quantidade de variáveis em termos de um número reduzido de fatores ou componentes. "Ao resumir os dados, a análise fatorial obtém dimensóes latentes que, quando interpretadas e compreendidas, descrevem os dados em um número muito menor de conceitos, do que as variáveis individuais originais (HAIR et al., 2009, p. 91)”

${ }^{6} \mathrm{O}$ teste $t$ é um teste paramétrico, ou seja, os dados a serem utilizados com essa técnica devem ser retirados de uma população com distribuição normal e um número significativo de casos. O teste $t$ é usado para saber a diferença entre dois grupos/entre as médias dos dois grupos, avaliando se existe uma diferença significativa entre as médias das duas condiçóes.

7 Hair et al. definem a regressão logística como uma "[...] forma especializada de regressão que é formulada para prever e explicar uma variável categórica binária (dois grupos)" (HAIR et al., 2009, p. 225).
} 
A Tabela 1 apresenta os valores do Kaiser-Meyer-Olkin (KMO) de adequabilidade da amostra e o Bartelett Test of Spherecity (BTS) da 51a Legislatura (1999-2003). O valor (KMO) varia entre 0 e 1 , e seu patamar crítico é de 0,60 . O valor de KMO da amostra é 0,646 , ou seja, superior ao patamar crítico. O teste de BTS deve ser estatisticamente significante $(\mathrm{p}<0,05)$ e o valor da amostra é de ( $\mathrm{p}<$ $0,000)$, portanto, possui significância estatística evidenciando a adequação da amostra para a análise fatorial.

Tabela 1 - KMO e Teste de Bartlett - Dimensão credibilidade (51 ${ }^{\text {a }}$ Legislatura)

\begin{tabular}{l|c|c}
\hline \multicolumn{2}{c}{ Kaiser-Meyer-Olkin medida de adequaçáo da amostragem } &, 646 \\
\hline \multirow{3}{*}{ Teste de esfericidade de Bartlett } & Aprox. Qui-quadrado & 425,802 \\
\cline { 2 - 3 } & Gl & 3 \\
\cline { 2 - 3 } & Sig. &, 000 \\
\hline
\end{tabular}

Fonte: Elaboração própria.

A Tabela 2 resume os valores da redução das variáveis (tempo no partido + cargos no partido + migração partidária). Foi gerado apenas um componente, formando a primeira dimensão credibilidade da $51^{\text {a }}$ Legislatura. $\mathrm{O}$ fator criado carrega 69,4\% da variância total (das três variáveis). A principal variável explicativa, a variável que mais contribui, é tempo no partido, seguida por cargos no partido e por migração partidária.

Tabela 2 - Total de variância assumida na dimensão credibilidade (51ª Legislatura)

\begin{tabular}{c|c|c|c}
\hline \multirow{2}{*}{ Componente } & \multicolumn{3}{|c}{ Autovalores iniciais } \\
\cline { 2 - 4 } & Total & \% de variância & \% acumulado \\
\hline $\mathbf{1}$ & 2,081 & 69,372 & 69,372 \\
\hline $\mathbf{2}$ &, 603 & 20,098 & 89,470 \\
\hline 3 &, 316 & 10,530 & 100,000 \\
\hline
\end{tabular}

Fonte: Elaboração própria.

Na sequência, a Tabela 3 apresenta os valores do Kaiser-Meyer-Olkin (KMO) de adequabilidade da amostra e o Bartelett Test of Spherecity (BTS) para a $51^{\mathrm{a}}$ Legislatura para a dimensão prestígio. $\mathrm{O}$ valor $\mathrm{KMO}$ para essa amostra é 0,516 , ou seja, abaixo do patamar crítico, porém o teste de BTS é estatisticamente significante $(\mathrm{p}<0,000)$. 
Tabela 3 - KMO e Teste de Bartlett - Dimensão prestígio (51ª Legislatura)

\begin{tabular}{c|c|c}
\hline \multicolumn{2}{c|}{ Kaiser-Meyer-Olkin medida de adequaçáo da amostragem } &, 516 \\
\hline \multirow{3}{*}{ Teste de esfericidade de Bartlett } & Aprox. Qui-quadrado & 216,420 \\
\cline { 2 - 3 } & gl & 3 \\
\cline { 2 - 3 } & Sig. &, 000 \\
\hline
\end{tabular}

Fonte: Elaboração própria.

A Tabela 4 resume os valores da redução das variáveis (tipo do candidato + tempo na Câmara + experiência política). $\mathrm{O}$ teste gerou 1 componente, formando a segunda dimensão (prestígio) para a 51 a Legislatura, o fator criado responde por $54,2 \%$ da variância total. A variável que mais contribui é tipo do candidato, seguida por tempo na câmara e experiência política.

Tabela 4 - Total de variância assumida - Dimensão prestígio (51ª Legislatura)

\begin{tabular}{c|c|c|c}
\hline \multirow{2}{*}{ Componente } & \multicolumn{3}{|c}{ Autovalores iniciais } \\
\cline { 2 - 4 } & Total & \% de variância & \% acumulado \\
\hline $\mathbf{1}$ & 1,626 & 54,210 & 54,210 \\
\hline $\mathbf{2}$ &, 963 & 32,105 & 86,316 \\
\hline 3 &, 411 & 13,684 & 100,000 \\
\hline
\end{tabular}

Fonte: Elaboração própria.

A Tabela 5 apresenta os valores do KMO e BTS para a 52a Legislatura (20032007). O valor KMO da amostra é 0,606 e o teste de BTS é estatisticamente significante $(\mathrm{p}<0,000)$, sugerindo adequação da amostra para estimação do modelo.

Tabela 5 - KMO e Teste de Bartlett - Dimensão credibilidade (52a Legislatura)

\begin{tabular}{l|c|c}
\hline \multicolumn{2}{c}{ Kaiser-Meyer-Olkin medida de adequaçáo da amostragem } &, 606 \\
\hline \multirow{2}{*}{ Teste de esfericidade de Bartlett } & Aprox. Qui-quadrado & 223,845 \\
\cline { 2 - 3 } & gl & 3 \\
\cline { 2 - 3 } & Sig. &, 000 \\
\hline
\end{tabular}

Fonte: Elaboração própria.

A Tabela 6, resume os valores da redução das variáveis (tempo no partido + cargos no partido + migração partidária), com a geração de um componente, formando dimensão credibilidade da $52^{\mathrm{a}}$ Legislatura. O fator gerado carrega $62,6 \%$ da variância. A principal variável é tempo no partido, seguida por cargos no partido e por migração partidária. 
184 | Leonardo de Morais, José Alexandre Júnior e Ranulfo Paranhos Filho

Tabela 6 - Total de variância assumida - Dimensão credibilidade (52a Legislatura)

\begin{tabular}{c|c|c|c}
\hline \multirow{2}{*}{ Componente } & \multicolumn{3}{|c}{ Autovalores iniciais } \\
\cline { 2 - 4 } & Total & \% de variância & \% acumulado \\
\hline $\mathbf{1}$ & 1,880 & 62,656 & 62,656 \\
\hline $\mathbf{2}$ &, 726 & 24,202 & 86,858 \\
\hline $\mathbf{3}$ &, 394 & 13,142 & 100,000 \\
\hline
\end{tabular}

Fonte: Elaboração própria.

A Tabela 7 sumariza os valores de KMO BTS para a 52a Legislatura para dimensão do prestígio. O valor KMO da amostra é 0,496 , ou seja, abaixo do patamar crítico de 0,60, todavia, o teste de BTS é estatisticamente significante ( $\mathrm{p}<0,000)$. Mesmo com o teste de adequabilidade da amostra (KMO) abaixo do patamar crítico de 0,60, optamos por manter as mesmas variáveis utilizadas no trabalho e, assim, aproximar o trabalho da replicação de Silva Jr. et al. (2013).

Tabela 7 - Teste de KMO e Bartlett - Dimensão Prestígio (52a Legislatura)

\begin{tabular}{l|c|c}
\hline \multicolumn{2}{c|}{ Kaiser-Meyer-Olkin medida de adequaçáo da amostragem } & ,496 \\
\hline \multirow{3}{*}{ Teste de esfericidade de Bartlett } & Aprox. Qui-quadrado & 241,668 \\
\cline { 2 - 3 } & gl & 3 \\
\cline { 2 - 3 } & Sig. &, 000 \\
\hline
\end{tabular}

Fonte: Elaboração própria.

Por fim, a Tabela 8 resume os valores da análise fatorial (tempo de câmara + experiência política + tipo do candidato). $\mathrm{O}$ teste gerou um componente, formando a segunda dimensão (prestígio) da 52 Legislatura, carregando $56,4 \%$ da variância compartilhada. A principal variável explicativa é tempo na Câmara, seguida por experiência política e por tipo do candidato.

Tabela 8 - Total de variância assumida - Dimensão prestígio (52a Legislatura)

\begin{tabular}{c|c|c|c}
\hline \multirow{2}{*}{ Componente } & \multicolumn{3}{|c}{ Autovalores iniciais } \\
\cline { 2 - 4 } & Total & \% de variância & \% acumulado \\
\hline $\mathbf{1}$ & 1,693 & 56,424 & 56,424 \\
\hline $\mathbf{2}$ &, 997 & 33,243 & 89,667 \\
\hline $\mathbf{3}$ &, 310 & 10,333 & 100,000 \\
\hline
\end{tabular}

Fonte: Elaboração própria.

Após a criação das dimensóes (credibilidade e prestígio), o próximo passo consiste em analisar a diferença entre as médias dos grupos (teste $t$ ). Essa etapa serve de preparação para aplicação de outra técnica (regressão logística). Analisamos a 
diferença entre as médias da disciplina de grupos comandados por líderes considerados críveis e não confiáveis, e líderes prestigiosos com não prestigiosos. Nossa aposta é que líderes mais confiáveis enfrentem um menor nível de indisciplina nas suas bancadas. O Gráfico 1 apresenta os resultados.

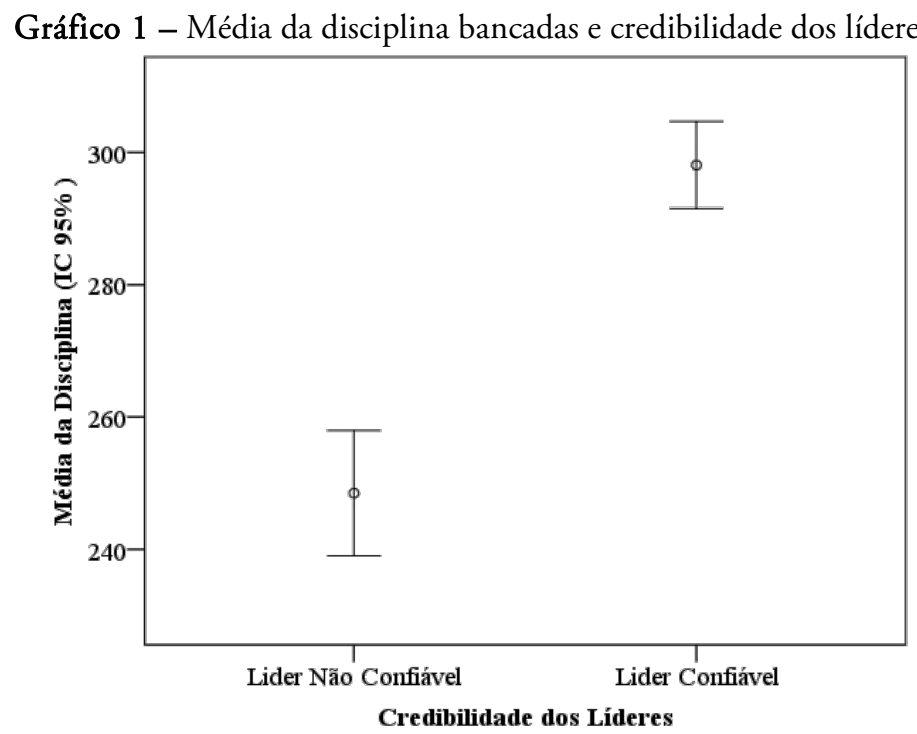

Fonte: Elaboração própria.

Tabela 9 - Teste da diferença entre as médias

\begin{tabular}{|c|c|c|c|c|c|c|c|c|c|}
\hline & \multicolumn{2}{|c|}{$\begin{array}{l}\text { Teste de } \\
\text { Levene }\end{array}$} & \multicolumn{7}{|c|}{ teste- $t$ para igualdade de médias } \\
\hline & \multirow[b]{2}{*}{$\mathrm{F}$} & \multirow[b]{2}{*}{ Sig. } & \multirow[b]{2}{*}{$\mathrm{t}$} & \multirow[b]{2}{*}{$\mathrm{gl}$} & \multirow[b]{2}{*}{ Sig. } & \multirow{2}{*}{$\begin{array}{c}\text { Diferença } \\
\text { média }\end{array}$} & \multirow{2}{*}{$\begin{array}{c}\text { Erro } \\
\text { padrão de } \\
\text { diferença }\end{array}$} & \multicolumn{2}{|c|}{ Intervalo } \\
\hline & & & & & & & & Inferior & Superior \\
\hline $\begin{array}{c}\text { Variância } \\
s \text { iguais }\end{array}$ & 3,457 &, 063 & $-8,108$ & 1346 &, 000 & $-49,595$ & 6,117 & $-61,595$ & $-37,595$ \\
\hline $\begin{array}{c}\text { Variância } \\
s \text { náo } \\
\text { iguais } \\
\end{array}$ & & & $-8,442$ & 775,863 &, 000 & $-49,595$ & 5,875 & $-61,127$ & $-38,063$ \\
\hline
\end{tabular}

Fonte: Elaboração própria.

A média de disciplina dos parlamentares com líderes mais confiáveis é mais alta. A falta de interseção entre os intervalos de estimação da média evidencia essa diferença. $\mathrm{O}$ teste de igualdade de variância (Levene) aponta a impossibilidade de assumir a igualdade de variância dos grupos. Porém, tanto o p-valor quanto o 
intervalo apontam existência de uma diferença estatisticamente significativa entre as médias de disciplina dos grupos. De acordo com as hipóteses da pesquisa, o nível de expertise do parlamentar escolhido para líder também fará diferença. Esperamos que bancadas lideradas por parlamentares mais preparados apresente menor nível de indisciplina. Utilizamos o procedimento de agrupar os parlamentares em função da expertise (prestígio) do seu líder. As tabelas abaixo apresentam os resultados.

Gráfico 2 - Média da disciplina de bancadas e prestígio dos líderes

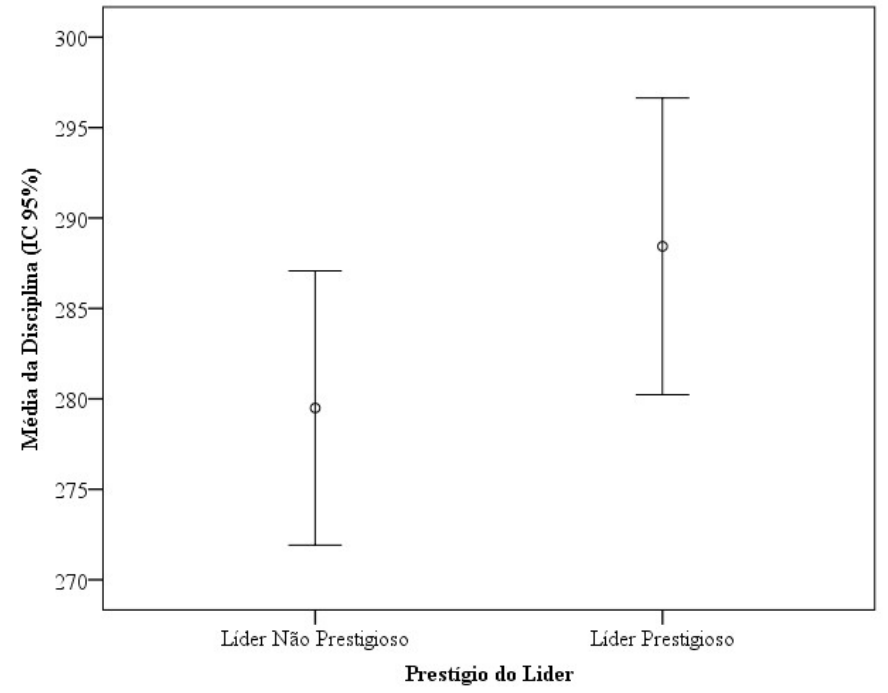

Fonte: Elaboração própria.

Tabela 10 - Teste de amostras independentes

\begin{tabular}{|c|c|c|c|c|c|c|c|c|c|}
\hline & \multicolumn{2}{|c|}{$\begin{array}{l}\text { Teste de } \\
\text { Levene }\end{array}$} & \multicolumn{7}{|c|}{ teste- $t$ para igualdade de médias } \\
\hline & \multirow[b]{2}{*}{$\mathrm{F}$} & \multirow[b]{2}{*}{ Sig. } & \multirow[b]{2}{*}{$\mathrm{t}$} & \multirow[b]{2}{*}{$\mathrm{gl}$} & \multirow[b]{2}{*}{ Sig. } & \multirow{2}{*}{$\begin{array}{c}\text { Diferença } \\
\text { média }\end{array}$} & \multirow{2}{*}{$\begin{array}{c}\text { Erro } \\
\text { padrão de } \\
\text { diferença }\end{array}$} & \multicolumn{2}{|c|}{ Intervalo } \\
\hline & & & & & & & & Inferior & Superior \\
\hline Variâncias iguais & 2,115 & ,147 & 1,063 & 472 & 288 & 7,351 & 6,915 & $-6,237$ & 20,940 \\
\hline $\begin{array}{l}\text { Variâncias náo } \\
\text { iguais }\end{array}$ & & & 1,052 & 385,715 & 293 & 7,351 & 6,989 & $-6,389$ & 21,092 \\
\hline
\end{tabular}

Fonte: Elaboração própria.

Embora os liderados por parlamentares mais preparados sejam mais disciplinados, a diferença entre as médias não é significativa. Há uma zona de interseção entre os intervalos estimados, demonstrando que a diferença entre as 
médias pode ser nula. $\mathrm{O}$ teste mostra que é possível assumir a igualdade de variância, porém tanto o p-valor quanto o intervalo aponta que insignificância estatística da diferença. Em resumo, é possível dizer que líderes mais confiáveis comandam bancadas mais disciplinadas, porém os mais prestigiosos não apresentam a mesma sorte. Mas o que dizer de bancadas lideradas por parlamentares que reúnem os dois atributos? No limite, essa pergunta busca observar se existe um efeito interativo entre as duas dimensôes.

Gráfico 3 - Média da disciplina de bancadas e credibilidade dos líderes

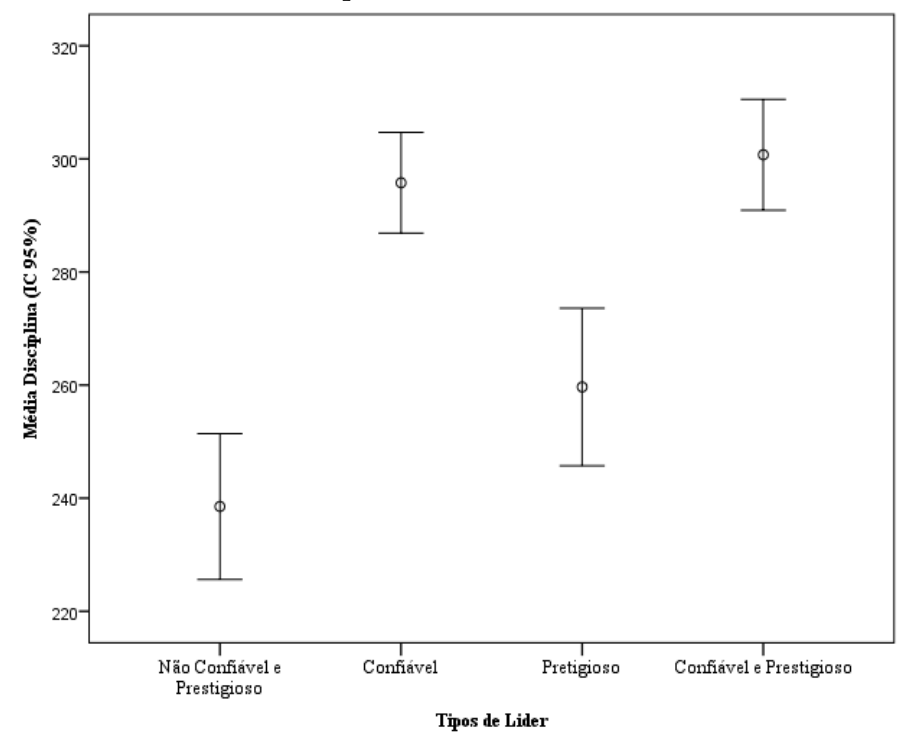

Fonte: Elaboração própria.

De acordo com o resultado, os líderes confiáveis e prestigiosos são os que enfrentam menor nível de indisciplina da bancada. No entanto, a diferença entre as médias de disciplina dos grupos liderados por parlamentares apenas confiáveis e confiáveis e prestigiosos não é significativa. Da mesma forma, a diferença entre bancadas com líderes não confiáveis e prestigiosos e apenas prestigiosos não é significativa. Em outros termos, o prestígio dos líderes parece não acrescentar muito a disciplina da bancada.

Para estabelecer um controle, o Gráfico 4 apresenta a média de disciplina em votaçôes cujo quórum exigido é dois terços. De acordo com a literatura, nessas 
188 | Leonardo de Morais, José Alexandre Júnior e Ranulfo Paranhos Filho

votaçôes há uma potencializaçáo do voto de cada parlamentar (FIGUEIREDO e LIMONGI, 2001).

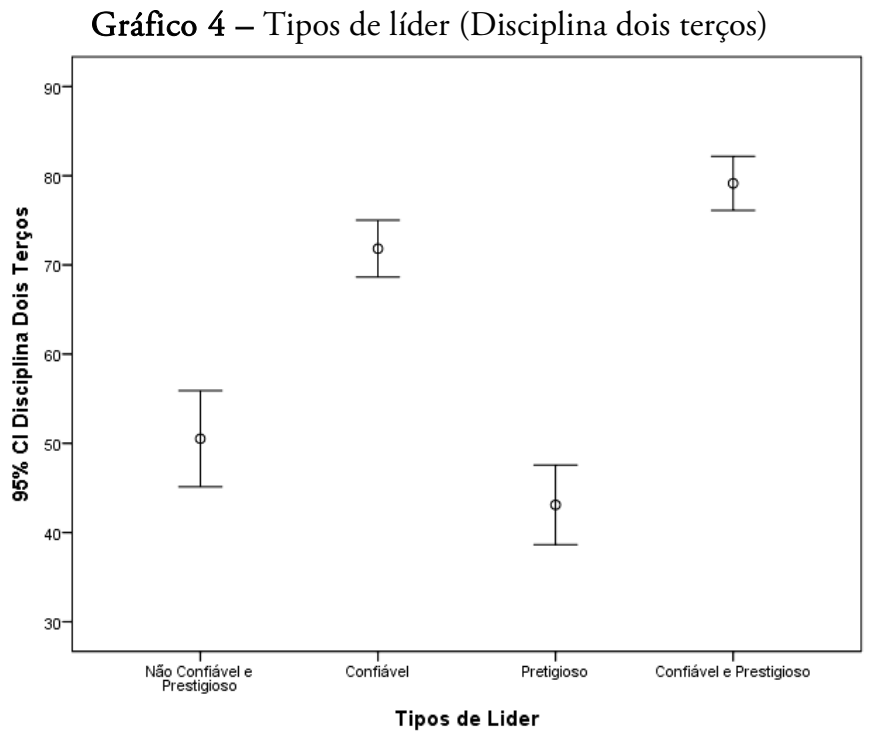

Fonte: Elaboração própria.

De acordo com os resultados, líderes confiáveis e prestigiosos coordenam bancadas mais disciplinadas, porém com média próxima de líderes apenas confiáveis. Apenas o prestígio do líder parece não exercer influência na disciplina da bancada. Surpreendentemente, líderes não confiáveis e prestigiosos apresentou uma média maior que bancadas lideradas por líderes prestigiosos. Para encerrar a análise das diferenças entre as médias, o Gráfico 5 sumariza a média da disciplina por tipos de líderes em votaçóes por maioria simples. 


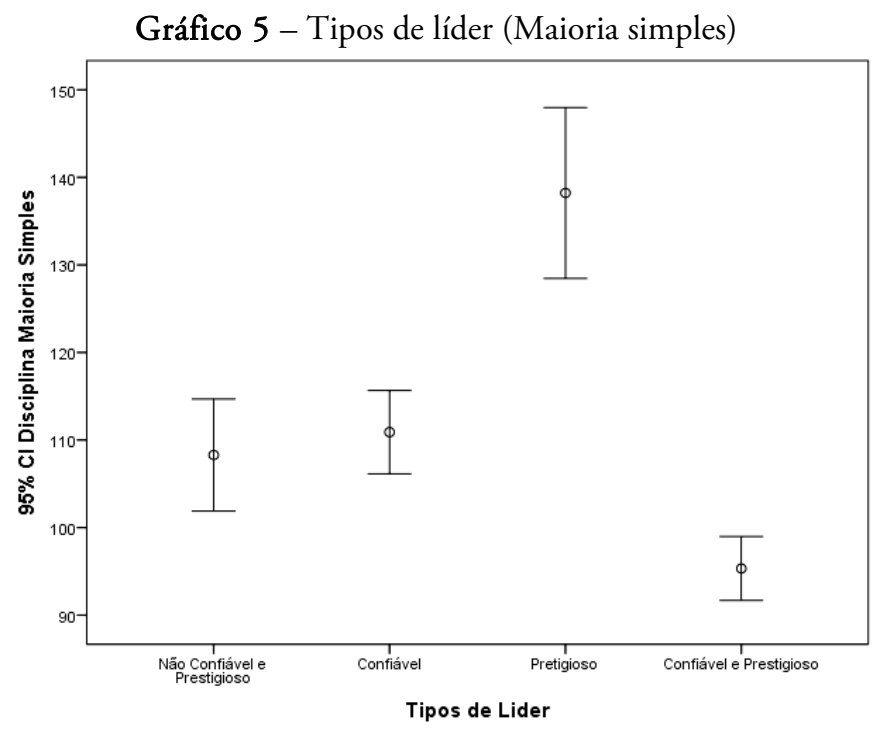

Fonte: Elaboração própria.

Nesse tipo de votação, o prestígio do líder apresentou uma média maior de disciplina que líderes confiáveis e prestigiosos (ver Gráfico 5), diferente de votaçóes por disciplina dois terços onde a média de líderes confiáveis e prestigiosos apresenta o pico da disciplina. Já a média de líderes confiáveis para os não confiáveis e prestigiosos, não apresenta diferença entre eles. Esse achado controverso indica que o prestígio pode importar para disciplinar as bancadas em votação cuja matéria tem impacto menor ${ }^{8}$. Além disso, é curioso o fato dos líderes confiáveis enfrentarem maior dificuldade para disciplinar suas bancadas nesse tipo de matéria. Uma possibilidade é que eles empreguem um esforço menor nesse tipo de situaçáo.

Até aqui, controlamos apenas características da liderança. Porém, a composição da bancada também pode fazer diferença. Em outros termos, possivelmente bancadas com maior nível de credibilidade e prestígio podem apresentar níveis mais altos de disciplina independentemente do perfil do seu respectivo líder.

Portanto, o próximo passo é utilizar a análise de regressão logística para estimar o efeito do perfil dos líderes sobre o nível de disciplina dos parlamentares.

\footnotetext{
${ }^{8}$ De acordo com Figueiredo e Limongi (2001), o quórum exigido para aprovação de uma matéria está fortemente correlacionado com o impacto que ela pode provocar na legislaçáo corrente. Quanto mais alto o quórum maior o impacto.
} 
Mais especificamente, o que nos interessa calcular é a razáo de chance de um parlamentar ser disciplinado a partir do perfil de quem os comanda. A Tabela 12 informa o resultado dos coeficientes estimados do modelo logístico para a dimensão credibilidade das $51^{\mathbf{a}}$ e $52^{\text {a }}$ Legislaturas.

Tabela 12 - Variáveis na equação (coeficientes) - Dimensão credibilidade

\begin{tabular}{c|c|c|c|c|c|c}
\hline Variável & B & S.E. & Wald & gl & Sig. & Exp(B) \\
\hline Credibilidade Líder &, 835 &, 140 & 35,641 & 1 &, 000 & 2,305 \\
\hline Cargo no partido &, 210 &, 146 & 2,066 & 1 &, 151 & 1,233 \\
\hline Tempo no partido &,- 006 &, 010 &, 347 & 1 &, 556 &, 994 \\
\hline Migraçáo partidária &,- 773 &, 132 & 34,396 & 1 &, 000 &, 462 \\
\hline Constante &,- 124 &, 150 &, 681 & 1 &, 409 &, 883 \\
\hline
\end{tabular}

Fonte: Elaboração própria.

A variável credibilidade do líder apresenta um efeito positivo $(0,835)$ sobre a probabilidade do parlamentar ser considerado disciplinado. Em termos percentuais, ser liderado por alguém com credibilidade eleva em $130,5 \%{ }^{9}$ a probabilidade de o parlamentar ser disciplinado ${ }^{10}$. A variável de controle cargo no partido apresenta um efeito positivo $(0,210)$ sobre a probabilidade da disciplina da bancada. Em termos percentuais, exercer cargo no partido eleva em $23,3 \%$ a probabilidade da disciplina da bancada. As demais variáveis de controle não apresentam significância estatística. A próxima tabela também informa o resultado dos coeficientes estimados do modelo logístico para dimensão prestígio.

Tabela 13 - Variáveis na equação (coeficientes) - Dimensão prestígio

\begin{tabular}{c|c|c|c|c|c|c}
\hline Variável & B & S.E. & Wald & gl & Sig. & Exp(B) \\
\hline Prestigio do líder &, 370 &, 120 & 9,599 & 1 &, 002 & 1,448 \\
\hline Tipo de candidato &,- 075 &, 162 &, 216 & 1 &, 642 &, 928 \\
\hline Experiência política &, 005 &, 122 &, 002 & 1 &, 969 & 1,005 \\
\hline Tempo na Câmara &,- 242 &, 065 & 13,616 & 1 &, 000 &, 785 \\
\hline Constante &, 115 &, 130 &, 793 & 1 &, 373 & 1,122 \\
\hline
\end{tabular}

Fonte: Elaboração própria.

\footnotetext{
${ }^{9}$ Fórmula para transformar o Exponencial em percentual $=(Q-1)^{*} 100$, onde, $Q$ é o coeficiente do exponencial.

${ }^{10}$ Vale lembrar que tanto a variável credibilidade do líder (independente) quanto disciplina da bancada (dependente) foram categorizadas via análise de cluster. Para primeira, o parâmetro foi o fator criado na análise fatorial explicada/analisada acima. Para a segunda, o parâmetro foi o número de vezes que o parlamentar votou conforme a indicação do líder.
} 
A variável prestígio do líder apresenta um efeito positivo $(0,370)$ sobre a probabilidade de o parlamentar ser considerado disciplinado. Em termos percentuais, ser chefiado por um líder prestigioso aumenta em $44,8 \%$ a probabilidade de o parlamentar pertencer ao grupo dos disciplinados. Além dessa variável, apenas o tempo na Câmara tem efeito significativo. Cada mandato a mais reduz 21,5\% a chance do parlamentar pertencer ao grupo dos disciplinados.

\section{Considerações finais}

Os resultados da pesquisa mostraram que a média de disciplina dos parlamentares com líderes mais confiáveis é mais alta. Porém, o mesmo não pode se dizer da média de disciplina dos parlamentares com líderes prestigiosos. Em resumo, líderes mais confiáveis comandam bancadas mais disciplinadas, já os mais prestigiosos não apresentam os mesmos resultados. Ao que parece, o que importa é a confiança que o líder inspira na bancada, o compromisso dele com o partido. Esse achado reforça a ideia de que o comportamento parlamentar tem um componente partidário como parte da literatura havia apontado (FIGUEIREDO e LIMONGI, 2001; LYNE, 2008). Por outro lado, o conhecimento da máquina junto a experiência dos líderes parecem não serem tão considerados. Provavelmente, essas características os tornam hábeis para negociar demandas (AMORIM e SANTOS, 2001). Mas é necessário algo que garanta que elas serão coletivas. Não sem razão, as bancadas lideradas por parlamentares confiáveis e prestigiosos são as que enfrentam menor nível de indisciplina.

Quando estabelecemos o controle pelo tipo de votação, naquelas que exigem 2/3 dos votos para aprovação, os líderes confiáveis e prestigiosos continuam coordenando bancadas mais disciplinadas. Surpreendentemente, nas votaçóes por maioria simples, a média da disciplina foi maior em bancadas comandas por líderes apenas prestigiosos. Provavelmente os líderes sabem que induzir o comportamento disciplinado não é como boiar no mar, ou seja, sabem que não é de graça. Por isso, devem concentrar os esforços em votação de maior peso.

Por fim, o modelo logístico aponta efeito significativo da credibilidade e do prestígio sobre a probabilidade do parlamentar ser classificado como disciplinado. Porém, a primeira tem um efeito maior. Adicionalmente, apenas os controles cargo no partido e tempo na Câmara apresentam significância estatística.

A pesquisa traz para a discussão não apenas a questão dos líderes de bancada, mas também inclui a análise do possível impacto dessa escolha na disciplina partidária dos parlamentares. Até onde sabemos, não existem trabalhos que examinem 
conjuntamente o perfil de liderança e liderados em nenhuma das duas Casas (Câmara ou Senado), embora o debate sobre a disciplina partidária seja amplo (AMES, 2003; AMORIM e SANTOS, 2001; CAREY, 2007; FIGUEIREDO e LIMONGI, 2001; LYNE, 2008; MAINWARING, 2001; NICOLAU, 2000). Vale dizer, essa é uma agenda da pesquisa que pode ser estendida para as duas últimas Legislaturas $\left(53^{\circ} \mathrm{e}\right.$ $54^{\circ}$ ), além disso, o modelo pode ser facilmente replicável para o Senado Federal.

- Leonardo Rodrigues de Morais é Mestrando em Ciência Política e Relações Internacionais, pela Universidade Federal da Paraíba. Email: leonardordm@hotmail.com.

- José Alexandre da Silva Júnior é Doutor em Ciência Política, pela Universidade Federal de Pernambuco. Professor do Instituto de Ciências Sociais (ICS) da Universidade Federal de Alagoas, Professor do Mestrado Profissional em Politicas Públicas da Universidade Federal de Pernambuco (UFPE). E-mail: jasjunior2007@yahoo.com.br.

Ranulfo Paranhos dos Santos Filho é Doutor em Ciência Política, pela Universidade Federal de Pernambuco. Professor do Instituto de Ciências Sociais (ICS) da Universidade Federal de Alagoas, Professor do Mestrado Profissional em Políticas Públicas da Universidade Federal de Pernambuco (UFPE). E-mail: ranulfoparanhos@me.com.

\section{Referências}

AMES, Barry. Os Entraves da Democracia no Brasil. Editora FGV, 2003.

AMORIM NETO, Octavio; SANTOS, Fabiano. A conexão presidencial: facçóes pró e antigoverno e disciplina partidária no Brasil. Dados. v. 44, n. 2, 2001. Disponível em: <http://dx.doi.org/10.1590/S0011-52582001000200003>. Acesso em: 15 mar. 2018.

BENDOR, Jonathan; GLAZER, Amihai; HAMMOND, Thomas H. Theories of Delegation. Annual Review Political Science. v. 4, p. 253-269, 2001. Disponível em: $<$ https://www.annualreviews.org/doi/pdf/10.1146/annurev.polisci.4.1.235>. Acesso em: 15 mar. 2018. 
CAREY, John M. Competing Principals, Political Institutions, and Party Unity in Legislative Voting. American Journal of Political Science, v. 51, n. 1, p. 92-107, 2007. Disponível em: <http://www.web.pdx.edu/ - mev/pdf/PS410_Readings_2014/Carey.pdf>. Acesso em: 15 mar. 2018.

COX, Gary W.; MCCUBBINS, Matthew D. Legislative Leviathan: Party Government in the House. University of California Press, 1993.

ELSTER, Jon. Peças e Engrenagem das Ciências Sociais. Rio de Janeiro: Relume-Dumará, 1994.

FIGUEIREDO, Maria Cheibub; LIMONGI, Fernando Papaterra. Executivo e Legislativo na Nova Ordem Constitucional. Rio de Janeiro: Editora FGV, 2001.

FREITAS, Andréa Marcondes. O presidencialismo da coalizão. São Paulo: USP, 2013. 168 f. Tese (Doutorado em Ciência Política) - Programa de Pós-Graduação em Ciência Política, Faculdade de Filosofia, Letras e Ciências Humanas, Universidade Federal de São Paulo, Sáo Paulo, 2013.

HAIR JR., Joseph; BLACK, William C.; BABIN, Barry; ANDERSON, Rolph; TATHAM, Ronald. Análise multivariada de dados. 6 ed. Bookman, 2009.

HINDESS, Barry. Rational choice theory and the analysis of political action. Economy and Society. v. 13, n. 3, p. 256-277, 1984 . Disponível em: <https://www.tandfonline.com/doi/abs/10.1080/03085148400000009>. Acesso em: 23 mar. 2018.

HIROI, Taeko; RENNÓ, Lucio. Institutional and partisan sources of legislative conflict: the Brazilian case. Revista Ibero-Americana de Estudos Legislativos, v. 3, n. 1, 2014. Disponível em: <http://bibliotecadigital.fgv.br/ojs/index.php/riel/article/view/18025>. Acesso em: 19 mar. 2018.

Meaning of time: legislative duration in the Brazilian congress. Textos Para Discussão Cepal/Ipea, v. 1, n. 228, p. 1-24, 2017. Disponível em: <http://ipea.gov.br/portal/images/stories/PDFs/TDs/ingles/dp_228.pdf>. Acesso em: 19 mar. 2018.

LUCAS, Kevin; SAMUELS, David. The ideological "coherence" of the Brazilian party system, 19902009. Journal of Politics in Latin America, v. 2, n. 3, p. 39-69, 2010. Disponível em: <https://journals.sub.uni-hamburg.de/giga/jpla/article/view/322>. Acesso em: 15 mar. 2018.

LYNE, Mona M. Proffering Pork: How party leaders build party reputations. American Journal of Political Science, v. 52, n. 2, p. 290-303, 2008. Disponível em: <http://onlinelibrary.wiley.com/doi/10.1111/j.1540-5907.2008.00313.x/abstract>. Acesso em: 15 mar. 2018.

MAINWARING, Scott P. Sistemas Partidários em Novas Democracias: o caso do Brasil. FGV, 2001.

MELO, Marcus André. A política da ação regulatória: responsabilização, credibilidade e delegação. Revista Brasileira de Ciências Sociais. v. 16, n. 46, p. 56-68, 2001. Disponível em: $<$ http://www.scielo.br/scielo.php?script=sci_arttext\&pid=S0102-

69092001000200003\&lng=en\&nrm=iso >. Acesso em: 15 mar. 2018.

NICOLAU, Jairo. Disciplina partidária e base parlamentar na câmara dos deputados no primeiro governo Fernando Henrique Cardoso (1995-1998). Dados, v. 43, n. 4, 2000. Disponível em: <http://www.scielo.br/scielo.php?.pid=S0011-52582000000400004\&script=sci_abstract\&tlng=pt>. Acesso em: 15 mar. 2018.

OLSON, Mancur. A lógica da açâo coletiva: os benefícios públicos e uma teoria dos grupos sociais. Universidade de São Paulo, 1999.

OSTROM, Elinor. Governing the commons: the evolution of institutions for collective action. Cambridge University Press, 1999. 
194 | Leonardo de Morais, José Alexandre Júnior e Ranulfo Paranhos Filho

PEREIRA, Carlos; MUELLER, Bernardo. Partidos fracos na arena eleitoral e partidos fortes na arena legislativa: a conexão eleitoral no Brasil. Dados, v. 46, n. 4, p. 735-771, 2003. Disponível em: $<$ http://www.scielo.br/scielo.php?pid=S0011-52582003000400004\&script=sci_abstract\&tlng=pt > Acesso em: 15 mar. 2018.

PEREIRA, Carlos; RENNÓ, Lucio. O que é que o reeleito tem? Dinâmicas político-institucionais locais e nacionais nas eleiçôes de 1998 para a Câmara dos Deputados. Dados, v. 44, n. 2, p. 133172, 2001. Disponível em: <http://www.scielo.br/scielo.php?script=sci_arttext\&pid=S001152582001000200004\&lng=en\&nrm=iso >. Acesso em: 15 mar. 2018.

SILVA JÚNIOR, Junior. A.; FIGUEIREDO FILHO, Dalson; PARANHOS, Ranulfo; ROCHA, Enivaldo. Quem controla o Legislativo? A ocupaçáo de cargos de comando na Câmara dos Deputados. Paraná Eleitoral, v. 2, n. 2, p. 283-308, 2013. Disponível em: <http://revistas.ufpr.br/pe/article/view/42769>. Acesso em: 15 mar. 2018.

Texto recebido em 30 de janeiro de 2018. Aprovado em 14 de março de 2018. 